\title{
ДОПОЛНИТЕЛЬНЫЕ КРИТЕРИИ ДИАГНОСТИКИ ЗЛОКАЧЕСТВЕННЫХ НОВООБРАЗОВАНИЙ НАДПОЧЕЧНИКОВ
}

Щербаков И.Е., Русаков В.Ф., Краснов Л.М., Черников Р.А., Слепцов И.В., Федоров Е.А., Чинчук И.К., Саблин И.В., Реброва Д.В., Федотов Ю.Н., Уварова М.А., Иванов А.В.

Новообразования надпочечников долгое время считались редким заболеванием, однако с развитием лучевой диагностики частота их выявления неуклонно растет. Агрессивность течения и значимое улучшение прогноза выживаемости при своевременном оперативном удалении злокачественных новообразований надпочечников делают актуальным вопрос ранней диагностики адренокортикального рака (АКР).

МАТЕРИАЛЫ И МЕТОДЫ: в исследование включено 28 больных с гормонально-неактивными новообразованиями надпочечников: 17 пациентов с адренокортикальными аденомами и $11-$ с АКР, 18 женщин и 10 мужчин в возрасте от 24 до 57 лет (38,2 29,6$)$. У 26 больных выполнена адреналэктомия, у 2 больных - биопсия без оперативного лечения (в связи с широкой распространенностью опухолевого процесса). Гистология оценивалась по критериям Weiss (2001), выполнено иммуногистохимическое исследование (ИГХ). До оперативного лечения оценивался уровень стероидов в суточной моче методом газовой хромато-масс-спектрометрии (ГХ-МС) на масс-спектрометре Shimadzu 2060.

РЕзУЛЬтАТЫ: по данным анализа было выявлено повышение уровней тетрагидро-11дезоксикортизола, дегидроэпиандростерона, прегнен-3ß,16a,20a-триол, прегнен-3a,16a,20a-триола, прегнандиола (P2), прегнантриола (Р3) и прегнентриола ( $\triangle \mathrm{P} 3)$, а также изменение соотношения P2/P3, характерные для АКР у женщин в постменопаузе и у мужчин. У женщин репродуктивного возраста повышение Р2 и Р3 может быть обусловлено фазой менструального цикла, в связи с чем в данной категории пациентов оценка этих показателей нецелесообразна. Чувствительность метода по совокупной оценке паттернов стероидогенеза в исследуемой группе составила 54,5\%, специфичность - 70,6\%.

Выводы: в исследуемой выборке чувствительность определения стероидного профиля мочи методом ГХ-МС оказалась низкой, что не позволяет применять данную методику какдополнительный критерий подтверждения злокачественного характера новообразования надпочечника. Тем не менее потенциальные возможности применения данного метода с целью наблюдения за пациентами после адреналэктомии по поводу АКР обуславливают необходимость дальнейшего изучения на большей выборке. 